\title{
Fetal Thymic Organ Culture
}

National Cancer Institute

\section{Source}

National Cancer Institute. Fetal Thymic Organ Culture. NCI Thesaurus. Code C19299.

Fetal Thymic Organ Culture. A cell culture system where fetal thymic cells are grown in vitro. 